Research Journal of Medical Sciences 13(3): 45-52, 2019

ISSN: $1815-9346$

(C) Medwell Journals, 2019

\title{
Isolation and Identification of Clinical Pseudomonas aeruginosa Producing Exotoxin A and Studying its Histipathotogic Effects in Mice
}

\author{
Mujahid Khalaf Ali \\ Department of Microbiology, College of Medicine, Tikrit University, Tikrit, Iraq
}

\begin{abstract}
Exotoxin A is an extracellular compound that is delivered by most clinical strains of Pseudomonas aeruginosa. It is a solitary chain polypeptide (Atomic weight, 71,000) with A and B pieces that intercede enzymatic and cell-restricting capacities, individually. Exotoxin A catalyzes the exchange of the adenosine diphosphate-ribosyl moiety from nicotinamide-adenine dinucleotide to lengthening factor 2 which brings about the inactivation of the last mentioned and the restraint of protein biosynthesis. This enzymatic action (ADP-ribosyl [ADPR]-transferase) is thought to represent the poisonous quality of exotoxin $\mathrm{A}$. The appropriation of the declaration of exotoxin an inside Pseudomonas animal varieties was inspected. Research center strains and clinical detaches of Pseudomonas aeruginosa were tried. The generation of exotoxin A was dictated by examining for ADPR-transferase movement in dialyzed solidified $\left(-20^{\circ} \mathrm{C}\right)$ and defrosted without cell supernatants from 22 -h societies or in 10-crease concentrated supernatants. The poison applied a stamped impact on the liver yet, evoked no self-evident minuscule changes in different organs. The infinitesimal injuries caused in the liver by a solitary infusion of two half deadly dosages (LD50) of poison (2.3 g) were portrayed by rot, cell swelling and greasy change inside $4-8 \mathrm{~h}$ and close aggregate hepatocellular necrosis at $48 \mathrm{~h}$.
\end{abstract}

Key words: Pseudomonas aeruginosa, exotoxin, histopathological effect, mice, isolation, identification

\section{INTRODUCTION}

Microorganisms creating diverse sorts of items through digestion of different kinds of substrates. A portion of these items considered as poisons which are normally delivered as definite results of digestion not as moderate, these poisons may aggregated inside the cell that known as endotoxin or discharged to development media known as exotoxin, these poisons can either be little peptide particles or proteins (Braun et al., 2000). Pseudomonas aeruginosa delivers substantial quantities of extracellular poisons which incorporate phytotoxic factor, shades, hydrocyanic corrosive, proteolytic catalysts, phospholipase, enterotoxin, exotoxin and sludge. The most vital factor in the pathogenicity of $P$. aeruginosa is the elaboration of a gathering of exotoxins (protein in nature). These exotoxins could cause leukopenia, acidosis, circulatory fall, rot of liver, aspiratory edema, discharge and tubular necrosis of kidneys (Petermann et al., 2001).

Latent organization of antidotal sera against these exotoxins can secure against deadly contaminations with $P$. aeruginosa without immunizer against the cell antigens. Pseudomonas aeruginosa is a shrewd pathogen that causes broad grimness and mortality in people who are immunocompromised or have fundamental restorative conditions, for example, urinary tract, respiratory tract and skin contaminations and essentially reasons for nosocomial diseases and it is every now and again impervious to ordinarily utilized anti-toxins and disinfectants (Phillips et al., 2003). P. aeruginosa was discovered just create exotoxin A which discharged ordinarily outside the cells. Pseudomonas aeruginosa Exotoxin A (ETA) has an ADP Ribosyltransferase (ADPRT) action (Liu, 1974). In eukaryotic cells, ETA catalysis the exchange of the ADP-ribose moiety from $\mathrm{NAD}^{+}$to prolongation Factor (EF-2). Subsequently, protein blend stops and inebriated cells kick the bucket, since, prolongation of polypeptide chains never again happens. Estimated time of arrival causes cell inebriation by means of a three-advance component (Liu and Wang, 1990). The step includes authoritative of ETA to a particular receptor, the a-macroglobulin receptor/low-thickness lipoprotein. The second step comprises of the disguise of the poison by target cells through endocytosis. In the third step, the poison is separated by a cell protease and translocated to the cytosol where it ADP-ribosylates EF-2. A superior comprehension of the system of activity of ETA was made conceivable by the portrayal of its three-dimensional structure (Pollack, 1983).

The regulation of ETA expression at the level of transcription iscomplex and involves a cascade of regulators that result in the maximalproduction of ETA in 
iron limiting environments. There are many factors affecting the synthesis and secretion of exotoxins A from these bacteria such as aeration, temperature, glycerol, media components as well as the concentration of iron in the media (Pollack, 2000).

Recently, regardless of the critical part of exotoxin A in the pathogenesis of $P$. aeruginosa. Be that as it may, contemplates on disconnects creating this poison are few particularly on a neighborhood scale regarding poisonous quality and adequacy factors influencing the generation and concentrate its belongings, so, this investigation came to ponder the cytogenetic impacts of $P$. aeruginosa ETA in mice. To accomplish such objective the accompanying advances were proposed.

Disconnection and distinguishing proof of $P$. aeruginosa from various contaminations delivering exotoxin A. Screening of separates for their profitability of exotoxin $\mathrm{A}$ and determination of most noteworthy delivering segregates. Incomplete filtration of exotoxin A utilizing diverse chromatographic systems. Study the cytogenetic effects of exotoxin A on mice depending onthe following measurements:

- Mitotic index

- Micronucleus

- Chromosomal aberration

- Sperm abnormalities

The study demonstrated that the exotoxin of Pseudomonas aeruginosa causes an early and rapidly increasing reduction in protein synthesis in the liver of the mouse. After 4 injection of the toxin, protein synthesis was inhibited by $50 \%$ within $2-4 \mathrm{~h}$ and inhibition was virtually complete before death. Although, a reduction in protein synthesis was noted in other organs, it occurred considerably later and to a significantly lesser extent. It appeared, therefore, that the toxin acted primarily on the liver. This observation was further investigated by determinations of the chronological sequence of histopathological changes in mouse tissues and of enzymatic changes in serum after injection of toxin.

\section{MATERIALS AND METHODS}

\section{Isolation and identification of Pseudomonas aeruginosa:}

Isolation 75 samples were collected from different types of infections (burn, wound, ear, sputum, UTI infections), during the period of $5 \backslash 12 \backslash 2011-18 \backslash 2 \backslash 2012$ from two hospitals in Baghdad (Chilled Center Hospital and AL-Yarmook Teaching Hospital), 150 isolates of different bacteria were obtained, oxidase and catalase tests was used to isolate genus of Pseudomonas and 60 isolates was obtained. The 3.1.2 identification 45 isolates suspected to be $P$. aeruginosa were selected from (60) isolates of Pseudomonas genus. Identification of $P$. aeruginosa isolates was done independently by utilizing a number of biochemical and cultural tests. $P$. aeruginosa was found to be motile, producing pyocianin (a water-soluble phenazing pigment on king $\mathrm{A}$ medium). Growth in brain heart infusion broth was intense at $41^{\circ} \mathrm{C}$ and no growth was found at $4^{\circ} \mathrm{C}$, oxidation of maltose and Mannitol, nitrate production, ornithine and arginine dearboxylation, indolphenol oxidation reaction and liquefaction of gelatin following the identification system suggested by Hugh and Gilardi (1980), $P$.aeruginosa differ from other species of Pseudomonas by growth in selective medium (cetramide agar), TSA medium and arginine dehydrolyse medium (Stavr, 1981). Bacterial colonies were grown on MacConkey agar medium which is differential medium because it distinguishes between lactose fermented and non-fermented bacteria, so, the bacteria appear pale color because it does not ferment lactose for testing blood hemolysis, selected bacterial colonies were grown on blood agar and degenerating of blood cells give an indication for hemolysis (Cruickshank et al., 1975) Fig. 1 shows different forms of growth in different media.

For characterization of $P$. aeruginosa from other Pseudomonas, number of biochemical tests were performed following the schematic diagram, these results shown in Table 1 which indicate that the isolates were positive for catalase, oxidase, hemolysis, growth at $42^{\circ} \mathrm{C}$, motility, pyocianin on cetrimide agar, gelatin liqufication and arginine dehydrolase and negative for gram-stain, growth at $4^{\circ} \mathrm{C}$, triple sugar, indol, methyl red, urease and MR-VP test. For assist affirmation of the recognizable proof, the disengages were subjected to Api-20E tests.

Location of exotoxin A: ELISA pack was utilized for location of exotoxin A delivered by segregates of Pseudomonas aeruginosa. Normal the copied perusing for every standard, control and test and subtract the normal zero standard optical thickness. Make a standard bend by diminishing the information utilizing $\mathrm{PC}$ programming equipped for creating a four parameter calculated (4-PL) bend fit. As an option, develop a standard bend by plotting the mean absorbance for every standard on the $\mathrm{x}$-hub against the focus on the $\mathrm{y}$-pivot draw a best fit bend through the focuses on the diagram. The information might be linearized by plotting the log of the PEA focuses versus the log of the OD. furthermore, the best fit line can be dictated by relapse investigation. This technique will deliver a satisfactory, yet, less exact attack of the information. On the off chance that examples 
Res. J. Med.Sci., 13 (3): 45-52, 2019

\begin{tabular}{|c|c|c|c|c|c|c|c|c|}
\hline \multirow[b]{2}{*}{$\begin{array}{l}\text { No. of } \\
\text { isolate }\end{array}$} & \multirow[b]{2}{*}{ Volume $(\mathrm{mL})$} & \multicolumn{4}{|c|}{ Protein concentration $(\mathrm{mg} / \mathrm{mL})$} & \multicolumn{3}{|c|}{ Toxin concentration $(\mathrm{ng} / \mathrm{mL})$} \\
\hline & & $\begin{array}{l}\text { Media } \\
\text { NTA free }\end{array}$ & $\begin{array}{l}\text { NTA conaining } \\
\text { media }\end{array}$ & $\begin{array}{l}\text { After percipient } \\
\text { by ammoiun } \\
\text { sulphate }\end{array}$ & $\begin{array}{l}\text { Purified protein from } \\
\text { NTA containing media } \\
\text { by DEAE-cellulose }\end{array}$ & $\begin{array}{l}\text { Media } \\
\text { NTA free }\end{array}$ & $\begin{array}{l}\text { NTA conaining } \\
\text { media }\end{array}$ & $\begin{array}{l}\text { Purified protein } \\
\text { from NTA } \\
\text { containing media }\end{array}$ \\
\hline PA 15 & 100 & 0.064 & 0.069 & 0.066 & 0.063 & 29.73 & 56.48 & 32.08 \\
\hline PA 11 & 100 & 0.040 & 0.049 & 0.047 & 0.044 & 23.31 & 41.05 & 26.11 \\
\hline PA 10 & 100 & 0.045 & 0.058 & 0.053 & 0.051 & 19.01 & 38.22 & 24.79 \\
\hline
\end{tabular}

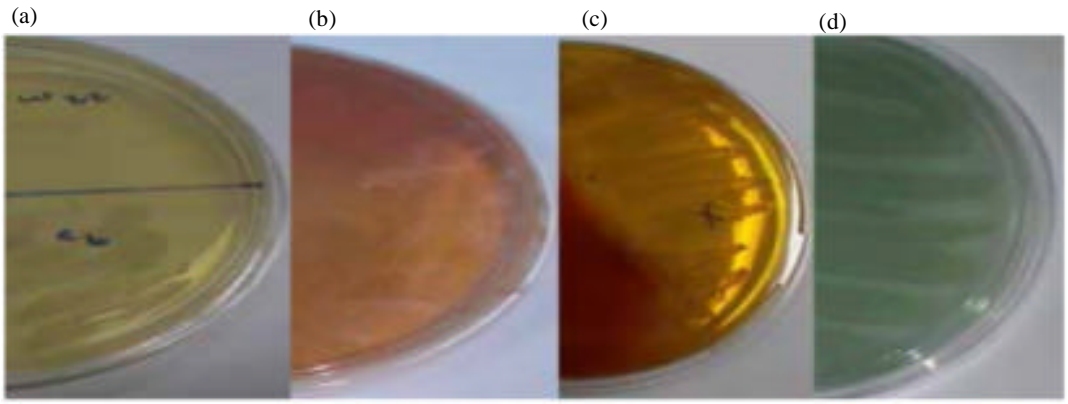

Fig. 1: Symbols represent growth in: a) Cetrmide agar; b) MacConky's agar; c) TSA agar and d) Nutrient agar

have been weakened, tha fixation read from the standard bend must be duplicated by the weakening variable. The 45 disengages just 25 were found to create exotoxin A. The pack was additionally utilized for focus estimation as the outcomes showed. Screening of these disengages demonstrates that, the vast majority of the detaches indicate positive outcomes. In any case, three segregates were chosen by their most elevated profitability and additionally their dissemination in various locales if diseases, three disconnects to be specific PA 10, PA 11 and PA 15 which deliver (23.31) (19.01) (29.73) ng $\backslash \mathrm{mL}$ and circulated in copy, UTI contamination and twisted separately.

These results were nearly agreed with Warren et al. who found that registered concentration between 0.3 and $0.6 \mathrm{ng} / \mathrm{mL}$ at least concentration (Walsh and Warren, 1979; Michael et al., 1991) found the maximum concentration detected by using ELISA approximately $0.75 \mu \mathrm{g} / \mathrm{mL}$ (Thompson et al., 1991).

Induction of exotoxin: A synthesis from previous results, it was shown that, the isolate PA1 5 capable of producing exotoxin A at concentration of $29.37 \mathrm{ng} / \mathrm{mL}$ which considered as basal synthesis. In order to improve synthesis, TSBD medium was amended with Nitrilotriacetic Acid (NTA) and then fallow productivity. Results show that protein focus was observed to be higher in societies contain NTA than that of free societies, this might be because of the capacity of NTA for hindering protease movement and thus stop protein turnover as revealed by a few research (Mandell et al., 2010).
Purification of exotoxin A: Number of purification steps were followed in order to obtainpure exotoxin A. These steps were reduced to minimum as long as the quantity of toxin is low and could be lost during purification. These steps are.

Precipitation of proteins by ammonium sulphate: With a specific end goal to focus the rough concentrate of poison and evacuate, however, much as could be expected water, ammonium sulfate was utilized at (10-90\%) immersion, the immersion proportion of $90 \%$ was hastened exotoxin A. This progression permits the salting out of atoms from water. Since, ammonium sulfate can kill charges at the surface of the protein and to disturb water layer encompassing the protein, it will in the end cause a reduction in the solvency of protein which thusly prompt the precipitation of the protein by the impact of salt. Ammonium sulfate is generally utilized on account of accessibility of ammonium sulfate, high dissolvability, minimal effort and it balances out the protein (Rahme et al., 1995).

Partial purified of exotoxin $A$ by ion-exchange chromatography: Purification of exotoxin A was done by ion-exchang echromatography using (DEAE-cellulose). The wash andelution of DEAE-cellulose column for three isolates. No exotoxin A wasdetected in the wash steps while the eluted fractions revealed. Results indicate the presence of three peaks. However, only one peak for eachelution of three isolates shows activity as detected by ELISA Kit. The amounts of partial purified proteins, 
Res. J.Med.Sci., 13 (3): 45-52, 2019
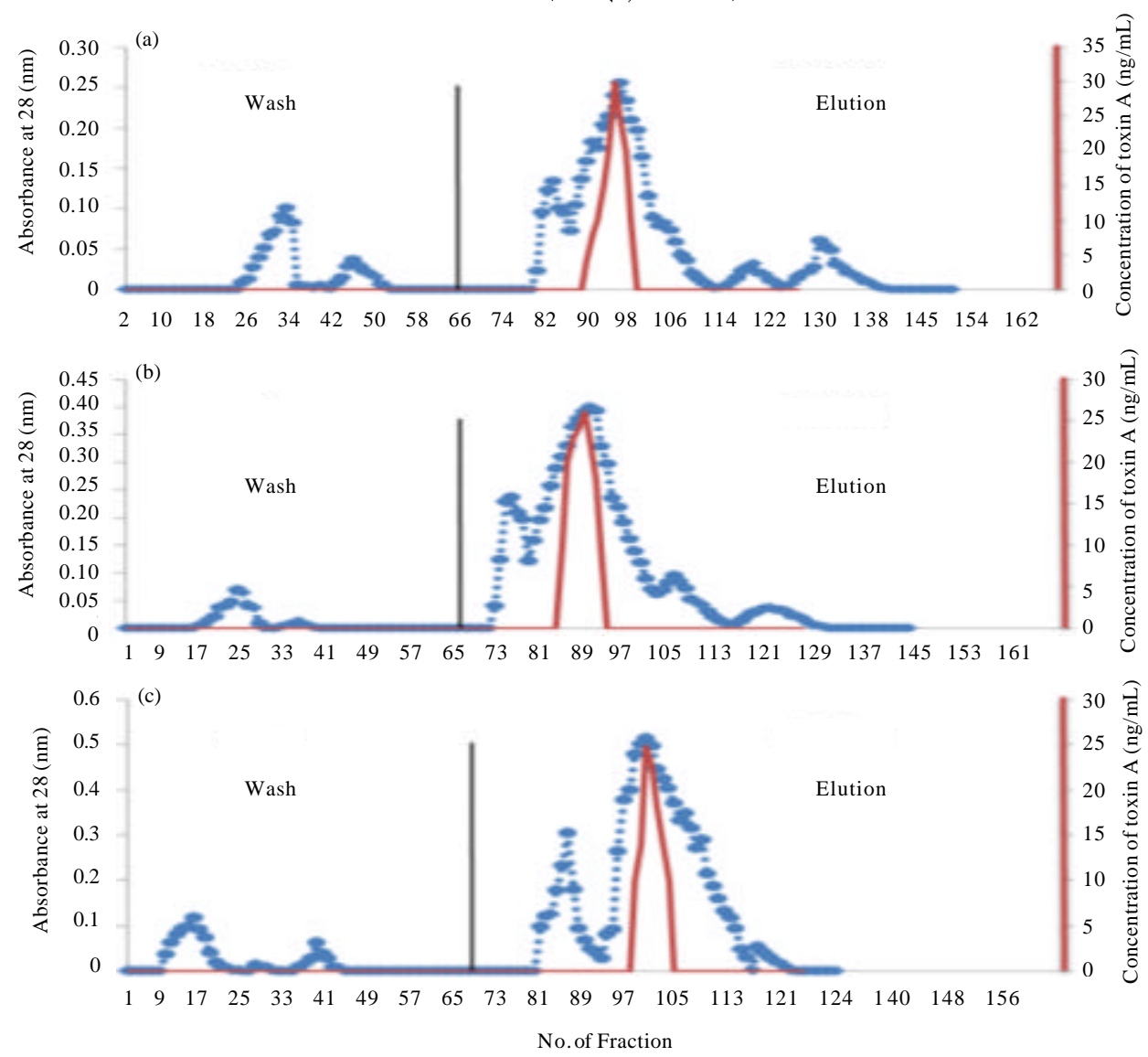

Fig. 2: Purification of exotoxin A produced from local isolates: a) IsolatePA 15; b) Isolate PA11 and c) Isolate PA 10, by DEAE-cellulose ion exchangechromatography column $(2 \times 18) \mathrm{cm}$ equilibrated with $0.01 \mathrm{M}$ Tris-HCL bufferPH 8.1, exotoxin eluted with linear salt gradient $0.1-1 \mathrm{M} \mathrm{NaCl}$, flow rate $45 \mathrm{~mL} / \mathrm{h}$

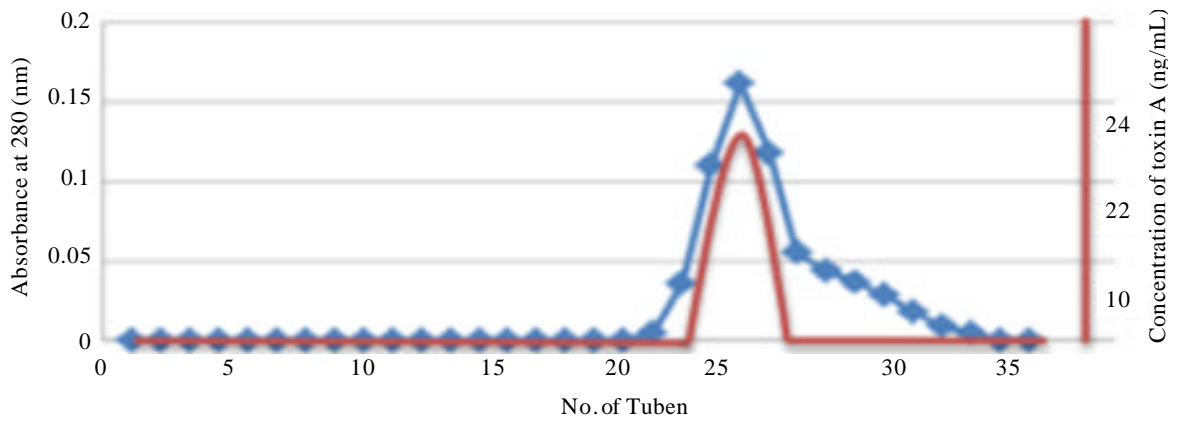

Fig. 3: Purification of exotoxin A by using Sepharose-4B column $(56 \times 1.5 \mathrm{~cm})$ with flow rate of $50 \mathrm{~mL} / \mathrm{h}$

indicate as much as $0.063,0.044$ and $0.051 \mathrm{mg} / \mathrm{mL}$ of protein produced by isolates PA15, PA11 and PA10, respectively (Fig. 2 and 3).

Detection of exotoxin: Detection of exotoxin in fractions eluted from ion-exchangechromatography was done using ELISA Kit, the results indicate the presence of only one peak in the elution steps of the three isolates giving positive result as measured spectrometrically at $450 \mathrm{~nm}$ wavelength. The results indicate that, isolate PA.15 is the highest producerfor exotoxin $\mathrm{A}$.

Purification of exotoxin a by gel filtration chromatography: The sample passed through Sepharose-4B then fractionated on the gel, fractions were collected up to 30 fractions. Exotoxin A was present 
infractions 21-23 depending on using acetic acid assay and increase absorbency of fractions. The result of purification showed the presence of one-peak (Fig. 3).

\section{RESULTS AND DISCUSSION}

Portrayal of Isogenic ETA-deficient mutants of 19660 and PAO1: A suicide vector was built conveying toxin A hindered with a $\Omega$ tape, encoding protection from chloramphenicol. Presentation of this vector into $P$. aeruginosa PAO1 or 19660 brought about a two fold homologous recombination occasion in which the disturbed toxin A quality was consolidated into the host genome Fig. 4.

Genomic DNA from PAO1 tox (-) and 19660 tox (-) and their respective isogenic parents was analyzed by Southern blot analysis at the region of the insertion of the chloramphenicol cassette within tox A. A probe was constructed by PCR to hybridize to tox $\mathrm{A}$ sequence upstream of the chloramphenicol cassette's insertion site. In the absence of the chloramphenicol cassette, the probe hybridized to a $1.5-\mathrm{kB}$ fragment of BamHI-digested DNA. Successful disruption of tox A resulted in a hybridization product of $700 \mathrm{bp}$ because of the presence of a BamHI site within the $\Omega$ cassette. The chloramphenicol tape was effectively identified inside tox $\mathrm{A}$ in BamHI-processed genomic DNA segregated from both PAO1 tox (-) and 19660 tox (-) with plasmidDNA from the tox A allelic trade vector pEXTOXA $\Omega$ filling in as a positive control. Genomic DNA segregated from isogenic guardians PAO1 and 19660 processed with BamHI and in addition plasmid DNA from pEXTOXA containing a wild-type duplicate of tox A brought about an anticipated hybridization result of $1.5 \mathrm{kB}$ (Fig. 5).
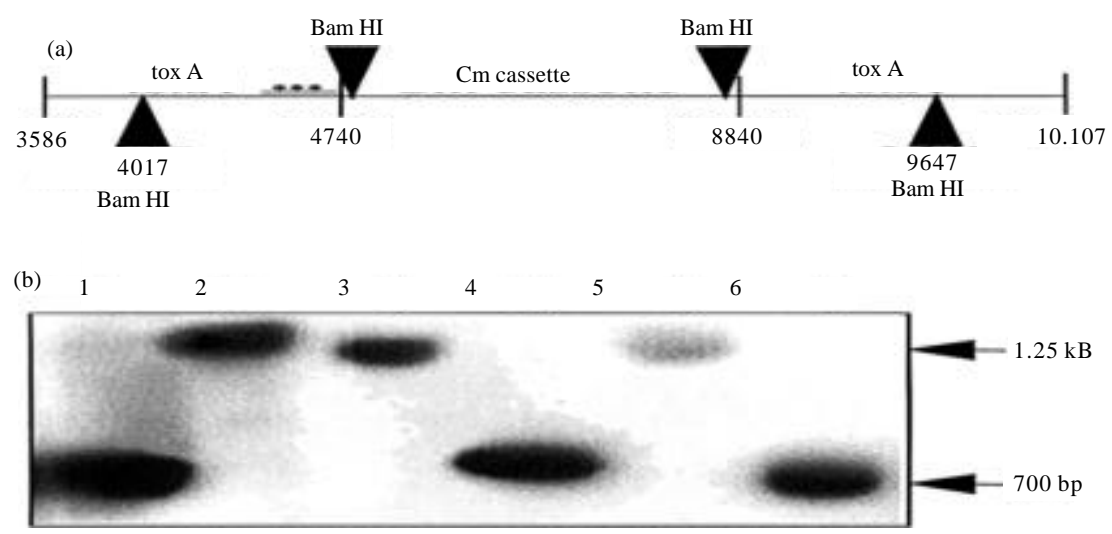

Fig. 4: Southern blot for the detection of the chloramphenicol resistance $(\mathrm{Cm})$ cassette within tox A: a) BamHI cut sites within tox A disrupted by the insertion of the Cm cassette on pEXTOXA $\Omega$. ***, probe hybridization site and $\mathrm{b}$ ) Blot of BamHI-digested DNA for the presence of the cm cassette. Lane 1: pEXTOXA ; Lane 2: pEXTOXA; Lane 3: PAO1; Lane 4: PAO1 tox (-); Lane 5: 19660 and lane 6:19660 tox (-)

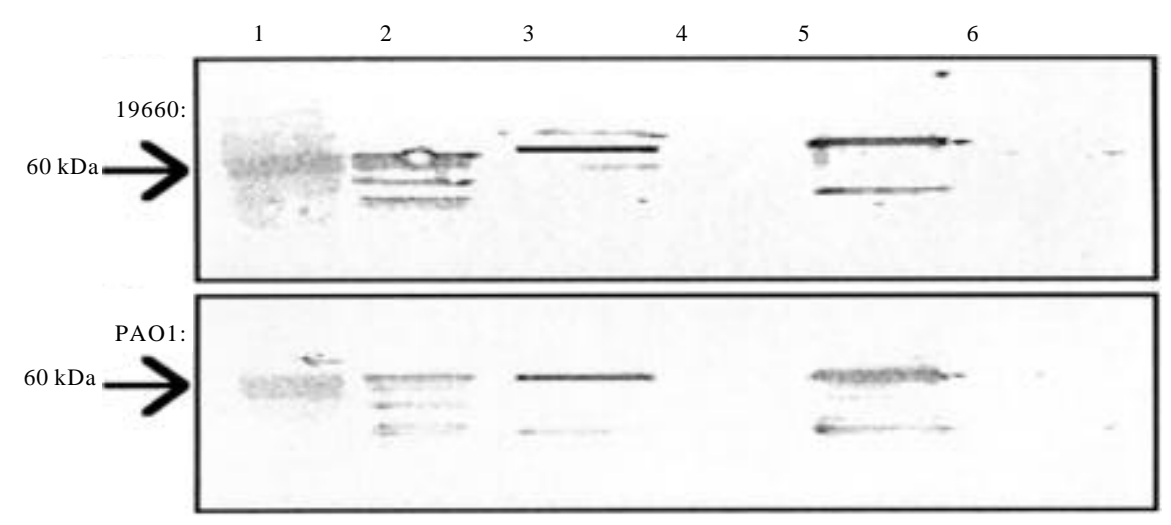

Fig. 5: Western smear for the location of ETA in culture supernatants of PAO1 and 19660. Path 1: sub-atomic weight marker; Path 2: unadulterated ETA (200 ng); Path 3: wild-type; Path 4: ETA mutant; Path 5: ETA mutant with pUCPTOXA and path 6: ETA mutant with pUCP21 
Supernatants were detached from societies of PAO1 tox (-), 19660 tox (-) and their individual wild-type isogenic parent strains developed under conditions ideal for ETA creation. The supernatants were then investigated by Western blotch examination for the location of ETA. Culture supernatants from wild-type PAO1 and 19660 contained immunoreactive protein, reliable with that saw with unadulterated ETA standard. No such item was identified in the supernatants disengaged from PAO1 tox (-) and 19660 tox (-).

The capacity of pUCPTOXA to reestablish ETA generation in these ETA-inadequate mutants was likewise affirmed by Western smear investigation. Presentation of pUCPTOXA into PAO1 tox (-) and 19660 tox (-) reestablished discharge of full-length ETA. Not surprisingly, culture supernatants from PAO1 tox (-) and 19660 tox (-) conveying vector control pUCP21 were negative for ETA by Western smear investigation.

Ocular virulence of ETA-deficient mutants of $P$. aeruginosa: The capacity of ETA-insufficient mutants of $P$. aeruginosa to hold fast to injured corneal epithelium was evaluated utilizing an in vitro organ culture show. Bacterial tallies produced using micrographs acquired through examining electron microscopy took into consideration the assurance of the microorganism's capacity to hold fast to tissue. No measurably noteworthy contrast $(\mathrm{p}=0.20)$ in mean disciple creatures per tallied field ( $\mathrm{n}=15$ ) was seen between wild-sort and ETA-insufficient mutants of either (PAO1, 9.5 \pm 1.5 ; PAO1 tox (-), 7.6 \pm 0.9$)$ or $(19660,16.7 \pm 2.3 ; 19660$ tox (-), $12.7 \pm 2.0$ ).

Assurance of the impact of ETA on the pathogenesis of Pseudomonas keratitis was made by analyzing the contaminations started by ETA-inadequate mutants in examination with those in their isogenic parent strains, utilizing a mouse model of bacterial keratitis. The 47 Fig. 4 aillustrates that disease with 19660 tox (-) brought about a factually huge abatement in mean clinical score at record-breaking focuses inspected $(n=20 ; p=0.001)$. In wild-type contaminated eyes at day $7 \mathrm{PI}$, the cornea punctured while mutant tainted eyes as of now point had recuperated. Articulation of tox A in trans in 19660 tox (-) brought about entire rebuilding of visual illness while the vector control displayed harmfulness like that with 19660 tox (-) (information not appeared). Comparative outcomes were gotten in mice tainted with PAO1 and PAO1 tox (-). Host response against $P$. aeruginosa ETA-deficient mutants.

The host reaction in the cornea against $P$. aeruginosa, contained fundamentally of $P M N$ s, can be quantitated by estimating the nearness of PMN-inferred
Myeloperoxidase (MPO) action in visual homogenate. As ahead of schedule as $24 \mathrm{~h} \mathrm{PI}$, essentially less ( $n=3$; $\mathrm{p}=0.05$ ) PMNs were distinguished in the homogenate of eyes contaminated with ETA-lacking mutants 19660 tox (-) and PAO1 tox (-). While PMN numbers in visual homogenate of ETA mutant contaminated mice stayed low, visual homogenate of wild-type tainted mice displayed expanding quantities of PMNs as the disease advanced.

Practicality of ETA-deficient mutants in vivo: The capacity of microscopic organisms to persevere in the cornea amid disease was dictated by serial weakening plating of visual homogenate from contaminated mice. As right on time as $24 \mathrm{~h} \mathrm{PI}$, there were altogether less microscopic organisms recuperated from eyes tainted with PAO1 tox (-) $(\mathrm{n}=3, \mathrm{p}=006)$. PAO1 tox (-) was cleared from the eye by $48 \mathrm{~h}$ PI. Altogether less suitable microscopic organisms were distinguished in 19660 tox (-)-tainted eyes at $36 \mathrm{~h} \mathrm{PI}(\mathrm{n}=3 ; \mathrm{p}=0.0005)$ and $<10$ $\mathrm{CFU} / \mathrm{mL}$ microorganisms were perceivable as late as $72 \mathrm{~h}$ PI.

Estimated time of arrival has been embroiled in the visual destructiveness of $P$. aeruginosa in light of past examinations exploring the cytotoxicity of ETA exogenously added to the eye and the decreased visual destructiveness in vivo of synthetically created mutants insufficient in ETA. The 15 results exhibited in this examination, coming about because of the development of isogenic mutants inadequate just in ETA, show conclusively that this protein is a factor in harmful visual ailment (Wang et al., 1994).

Since, no noteworthy contrast in visual ailment was seen in this investigation right on time amid contamination between ETA-inadequate mutants and their separate wild-type strains, we estimated that ETA itself has no basic part in adherence of $P$. aeruginosa to scarified corneal epithelium. Results from the examination of ETA-lacking mutants in an in vitro organ culture model of bacterial adherence bolster this speculation.

The noteworthy contrast in illness between ETA-insufficient mutants and their separate isogenic guardians after the disease is set up, corresponds with the freedom of $P$. aeruginosa that is unequipped for communicating enzymatically dynamic ETA. Our information show that microscopic organisms are equipped for clinging to the cornea and surviving right on time amid the contamination, paying little heed to generation of ETA, yet that ETA's nonattendance influences their capacity to continue and cause malady (Rahman, 2006). Albeit both ETA-lacking strains of $P$. aeruginosa analyzed in this examination were in the end cleared, the 19660 ETA mutant could manage disease 
tantamount to its wild-type parent strain longer than the PAO1 ETA mutant and was not cleared as proficiently as the PAO1 ETA mutant. These distinctions might be because of the capacity of cytotoxic strains, for example, 19660 to create an intense cytotoxin assigned ExoU which intrusive strains, for example, PAO1 don't deliver. ExoU has been connected to an intense cytotoxicity displayed by $P$. aeruginosa against lung epithelium. It is conceivable that the exercises of ExoU right on time amid contamination represent the postponed leeway and raised illness scores saw amid disease with 19660 tox (-) in correlation with PAO1 tox (-) (Koshurnikova et al., 2000).

One conceivable clarification for the powerlessness of ETA-insufficient $P$. aeruginosa to hold on in the eye is that ETA may influence the physiology of the corneal epithelium at or close to the underlying injury site. In a corneal injury, there is an underlying time of cell revamping joined by a lot of protein combination. Effective restoration of the epithelium is subject to the union of cytoskeletal parts (e.g., actin, talin, surface-related glycoproteins and glycolipids) and other cell surface atoms, for example, CD44. It is conceivable that within the sight of ETA, union of these proteins is blocked. Estimated time of arrival could likewise restrain the creation of development factors, for example, Epidermal development Factor (EGF), Hepatocyte development Factor (HGF) and changing development Factor (TGF)- $\beta 1$ which are connected to the control of corneal epithelial movement, development and attachment. The resultant restraint of wound mending would advance the support of contamination by uncovering new restricting locales for bacterial colonization past the underlying injury site (Kanack et al., 2006).

The freedom of ETA-lacking $P$. aeruginosa may likewise be credited to ETA's tweaking the host incendiary reaction. Estimated time of arrival has been accounted for to affect the superstructure of PMNs and is equipped for initiating the oxidative burst of monocytes, an action related with tissue harm in the eye. Miyazaki et al. shown that ETA is harmful to PMNs in vivo and furthermore represses the capacity of PMNs to phagocytose and slaughter $P$. aeruginosa. Besides, ETA can affect the host reaction by impacting the prompt cytokine condition. Determination of $P$. aeruginosa keratitis relies upon a sensitive harmony between generation of cytokine arbiters that either advance $\mathrm{c}$ or reduce an intense $\mathrm{PMN}$ reaction in the eye.

\section{CONCLUSION}

Finding the instrument by which ETA influences diligence of $P$. aeruginosa in the eye is a vital advance in understanding the atomic reason for the harmfulness of
$P$. aeruginosa. Notwithstanding its system, ETA has all the earmarks of being a potential restorative focus in the treatment of Pseudomonas keratitis.

\section{REFERENCES}

Birkenmeier, G., I. Kaempfer, J. Kratzsch and W. Schellenberger, 1998. Human leptin forms complexes with a 2-macroglobulin which are recognized by the alpha 2-macroglobulin receptor/low density lipoprotein receptor-related protein. Eur. J. Endocrinol., 139: 224-230.

Braun, P., W. Bitter and J. Tommassen, 2000. Activation of Pseudomonas aeruginosa elastase in Pseudomonas putida by triggering dissociation of the propeptide-enzyme complex. Microbiol., 146: 2565-2572.

Cruickshank, R., J.P. Duguid, B.P. Mariom and R.H.A. Swain, 1975. Medical Microbiology the Practice of Medical Microbiology. 12th Edn., Churchill Livingstone, London, New York.

Hugh, R. and G.L. Gilardi, 1980. Pseudomonas. In: Manual of Clinical Microbiology, Lennette, E.H., A. Balows, W.J. Hausler, Jr. and J.P. Truant (Eds.). American Society for Microbiology, Washington, DC., USA., pp: $288-317$

Kanack, K.J., L.J. Runyen-Janecky, E.P. Ferrell, S.J. Suh and S.E.H. West, 2006. Characterization of DNA-binding specificity and analysis of binding sites of the Pseudomonas aeruginosa global regulator, $\mathrm{Vfr}$, a homologue of the Escherichia coli cAMP receptor protein. Microbiology, 152: 3485-3496.

Koshurnikova, N.A., E.S. Gilbert, M. Sokolnikov, V.F. Khokhryakov and S. Miller et al., 2000. Bone cancers in Mayak workers. Radiat. Res., 154: 237-245.

Liu, P.V. and S. Wang, 1990. Three new major somatic antigens of Pseudomonas aeruginosa. J. Clin. Microbial., 28: 922-925.

Liu, P.V., 1974. Extracellular toxins of Pseudomonas aeruginosa. J. Infect. Dis., 130: S94-S99.

Mandell, G.L., J.E. Bennett and R. Dolin, 2010. Mandell, Douglas and Bennett's Principles and Practice of Infectious Diseases. 7th Edn./Vol. 2, Churchill Livingstone, ?London, England, UK., ISBN:9780443068393, Pages: 4028.

Petermann, S.R., C. Doetkott and L. Rust, 2001. Elastase deficiency phenotype of Pseudomonas aeruginosa canine otitis externa isolates. Clin. Diagn. Lab. Immunol., 8: 632-636.

Phillips, R.M., D.A. Six, E.A. Dennis and P. Ghosh, 2003. In vivo phospholipase activity of the Pseudomonas aeruginosa cytotoxin ExoU and protection of mammalian cells with phospholipase A2 inhibitors. J. Biol. Chem., 278: 41326-41332. 
Pollack, M., 1983. The role of exotoxin a in Pseudomonas disease and immunity. Rev. Infect. Dis., 5: S979-S984.

Pollack, M., 2000. Pseudomonas aeruginosa. In: Principles and Practice of Infectious Diseases, Mandell, G.L., J.E. Bennett and R. Dolin (Eds.). Churchill Livingstone, Philadelphia, Pennsylvania, pp: $2310-2335$.

Rahman, M.F., 2006. Genetic analysis of protease from Pseudomonas aeruginosa isolated from different human infections. MSc Thesis, University of Babylon, Hillah, Iraq.

Rahme, L.G., E.J. Stevens, S.F. Wolfort, J. Shao and R.G. Tompkins et al., 1995. Common virulence factors for bacterial pathogenicity in plants and animals. Sci., 268: 1899-1902.
Stavr, M.P., 1981. The Prokaryotes: A Handbook on Habitats, Isolation and Identification of Bacteria. Springer, Berlin, Germany, ISBN:9780387088716, Pages: 2440.

Thompson, M.R., J. Forristal, P. Kauffmann, T. Madden and K. Kozak et al., 1991. Isolation and characterization of Pseudomonas aeruginosa exotoxin a binding glycoprotein from mouse LM cells. J. Biol. Chem., 266: 2390-2396.

Walsh, J.A. and K.S. Warren, 1979. Selective primary health cares an interim strategy for disease control in developing countries. N. Engl. J. Med., 301: 967-974.

Wang, Q., G. Xu and J. Li, 1994. Assay of R-plasmid and antibiotic resistance spectrum in 286 strains of gram-negative bacteria. Zhonghua Liuxingbingxue Zazhi, 15: 357-359. 